\title{
FAKTOR- FAKTOR YANG BERASOSIASI PADA KEJADIAN STUNTING PADA BAYI DI BAWAH DUA TAHUN DI WILAYAH KERJA PUSKESMAS PANDRAH KABUPATEN BIREUEN
}

\author{
Aida Fitriani ${ }^{1}$, Dida A. Gurnida ${ }^{2}$, Anita Rachmawati ${ }^{3)}$ \\ 1)Program Studi Magister Kebidanan FK Unpad \\ 2) Departemen Obstetri dan Ginekologi FKUnpad/RSHS \\ 3) Departemen Ilmu Kesehatan Masyarakat FK Unpad \\ E-mail : fitrianiaida82@gmail.com
}

\begin{abstract}
Stunting is a condition of physical growth failure characterized by height for age under -2 SD from the WHOchart growth standard. This study used adesign cross sectional with variables of birth weight, nonexclusive breastfeeding, maternal education, education. father, bistory of ANC visits, socio-economic history, and work history of parents. This study used a sample of 56 baduta who were stunting. The sample in this study, namely mothers who have baduta. This study uses instruments in the form of a questionnaire and an infantometer. Data analysis used univariable analysis, bivariable analysis with chi square test and multivariable with logistic regression analysis. The results showed that the prevalence of stunting in the study site was $31.8 \%$, the factor most associated with stunting in the ANC visit was POR $=10.54$ (95\% CI: 4.20-25.03) p value $=<0.001$. The dominant factor associated with stunting was the visit bistory of ANC POR 10.54 (95\% CI: 4.20-25.03) with $p$ value $=<0.001$. ANC visit bistory is the dominant factor associated with stunting.
\end{abstract}

Keywords: Stunting; bistory of exclusive breastfeeding; bistory of ANC visits.

\begin{abstract}
ABSTRAK
Stunting merupakan kondisi kegagalan pertumbuhan fisik yang ditandai dengan kondisi tinggi badan menurut umur berada dibawah -2 SD dari grafik WHO growth standart. Penelitian ini menggunakan desain cross sectional dengan variabel berat badan lahir, pemberian ASI tidak Ekslusif, pendidikan ibu, pendidikan bapak, riwayat kunjungan ANC, riwayat sosial ekonomi, serta riwayat pekerjaan orang tua. Kriteria inklusi pada penelitian ini adalah anak umur 6-23 bulan, sehat dan tidak mengalami cacat bawaan serta mendapat
\end{abstract}

Cara mengutip: Fitriani, Aida., Gurnida, Dida A., \& Rachmawati, Anita. (2020). Faktor-faktor yang Berasosiasi pada Kejadian Stunting pada Bayi di bawah dua tahun di wilayah kerja Puskesmas Pandrah Kabupaten Bireuen. Care:Jurnal Ilmiah Ilmu Kesehatan, $8(3), 483-492$ 
persetujuan orang tua. Penelitian ini menggunakan sampel sebanyak 56 ibu yang mempunyai baduta yang stunting. Penelitian ini menggunakan instrumen dalam bentuk kuesioner dan infantometer. Analisis data menggunakan analisis univariabel, bivariabel dengan uji chi square dan multivariabel dengan analisis regresi logistik. Hasil penelitian menunjukkan prevalensi stunting ditempat penelitian sebesar $31,8 \%$, faktor yang paling berhubungan dengan stunting kunjungan ANC POR=10,54(IK 95\%:4,20-25,03) nilai $\mathrm{p}=<0,001$. Faktor dominan yang berhubungan dengan stunting adalah riwayat kunjungan ANC POR 10,54 (IK95\%:4,20-25,03) dengan nilai $\mathrm{p}=<0,001$. Riwayat kunjungan ANC merupakan faktor dominan yang berhubungan dengan stunting.

Kata Kunci: Stunting, riwayat pemberian ASI Ekslusif; riwayat kunjungan ANC.

\section{PENDAHULUAN}

Masalah kurang gizi kronis stunting (pendek) merupakan masalah yang menyita banyak perhatian dalam beberapa tahun terakhir.Istilah stunting pertama kali dikemukan oleh Warterlow pada tahun 1970 untuk menggambarkan hambatan pertumbuhan panjang badan sehingga menghasilkan anak bertubuh pendek yang tidak sesuai dengan usiannya. Kemiskinan, rendahnya pendidikan, kesehatan ibu hamil serta kesehatan bayi yang baru lahir sampai anak berusia dua tahun dinilai berkaitan erat dengan kejadian stunting. Masa anak-anak merupakan masa yang sangat penting. Masa ini merupakan masa pertumbuhan dan perkembangan anak yang sangat pesat di bawah lima tahun, akan berdampak seumur hidup sepanjang daur kehidupan. Kekurangan gizi pada baduta menyebabkan sel otak berkurang $15 \%$ - 20\%, sehingga kualitas otak anak hanya sekitar $80 \% \quad-\quad 85 \%$, yang berdampak pada kognitif, sehingga anak sulit belajar dan menyerap informasi, baik secara akademik maupun non akademik, karena kekurangan nutrisi sejak dini, akan berdampak ke tingkat intelegensinya lebih rendah. berdampak pada kognitif di masa yang akan datang. Menurut data World Health Organisation (WHO) stunting di Indonesia berada pada urutan nomor lima terbesar dunia dan Indonesia masih mengalami kejadian stunting lebih tinggi(37\%) hampir 9 juta anak bawah dua tahun mengalami stunting dibanding dengan negara-negara lain di Asia Tenggara, seperti Myanmar (35\%), Vietnam (23\%), dan Thailand (16\%). Pertumbuhan adalah proses berkelanjutan yang dimulai dari konsepsi hingga dewasa. Stunting adalah salah satu kondisi kegagalan pertumbuhan fisik yang ditandai dengan tinggi badan berdasarkan usia. Pengerdilan terjadi ketika tinggi badan berdasarkan skor $\mathrm{z}<-2 \mathrm{SD}$ dan pengerdilan berat jika skor $z<-3$ SD.

Pengerdilan terjadi sebagai dampak dari malnutrisi kronis selama 1.000 hari 
pertama kehidupan. Ini adalah prediktor sumber daya manusia yang buruk, sehingga mengurangi kemampuan produktif suatu negara di masa depan. Selain itu, mereka menghadapi kemungkinan yang lebih besar untuk hidup sebagai orang dewasa yang kurang pendidikan, miskin, tidak sehat, dan lebih rentan terkena penyakit tidak menular seperti obesitas, hipertensi, dan diabetes. berat lahir, riwayat menyusui, pendidikan orang tua, riwayat kunjungan ANC, pekerjaan orang tua dan sosial ekonomi adalah penyebab langsung anak malnutrisi.

Tren kejadian Stunting pada baduta di Aceh terus meningkat kedua tertinggi di Kabupaten Bireuen (31,07\%) Kecamatan Pandrah termasuk wilayah status gizi serius dalam kategori tinggi. Prevalensi tahun 2018 karena angka stunting tinggi $(32,76 \%)$ dan balita pendek adalah $32,76 \%$ dan BBLR menduduki peringkat pertama seKabupaten Bireuen.

\section{METODE PENELITIAN}

Penelitian ini menggunakan rancangan observasional analitik, dengan desain cross sectional. Rancangan ini dilakukan untuk mencari hubungan antara faktor- faktor berat badan lahir,pemberian ASI Ekslusif, pendidikan orang tua, riwayat kunjungan ANC, riwayat pekerjaan orang tua dan sosial ekonomi keluarga dengan kejadian stunting. Penelitiandilaksanakan di di Puskesmas Pandrah Kabupaten Bireuen. Populasi penelitian semua ibu yang ada anak usia 0-23 sampelnya 176 dengan anak yang stunting 56 orang dan yang tidak stunting/normal 120 orang.. Cara pengumpulan data menggunakan data primer dan sekunder. Data diolah dan kemudian dianalisis dengan analisis bivariat menggunakan uji Chi Square dan analisis multivariat menggunakan regresi logistik ganda.

\section{HASIL}

Tabel 1. Prevalensi Stunting Pada Anak Umur 6-23 Bulan di Wilayah Kerja Puskesmas Pandrah Kabupaten Bireuen Tahun 2019

\begin{tabular}{lcc}
\hline Kejadian Stunting & $\mathbf{N}$ & $\mathbf{( \% )}$ \\
\hline Stunting & 56 & 31,8 \\
Tidak stunting & 120 & 68,2 \\
\hline \multicolumn{3}{l}{ Keterangan: Prevalensi Stunting (IK95\%): } \\
31,8\% (25,4\%-39\%)
\end{tabular}

Berdasarkan Tabel 1 dapat dilihat bahwa prevalensi stunting pada anak umur 6-23 bulan diwilayah kerja Puskesmas Pandrah Kabupaten Bireuen sebesar $31,8 \%$. 
Tabel 2. Karakteristik Keluarga dengan Kejadian Stunting Pada Anak Umur 6-23 Bulan di Wilayah Kerja Puskesmas Pandrah Kabupaten Bireuen Tahun 2019

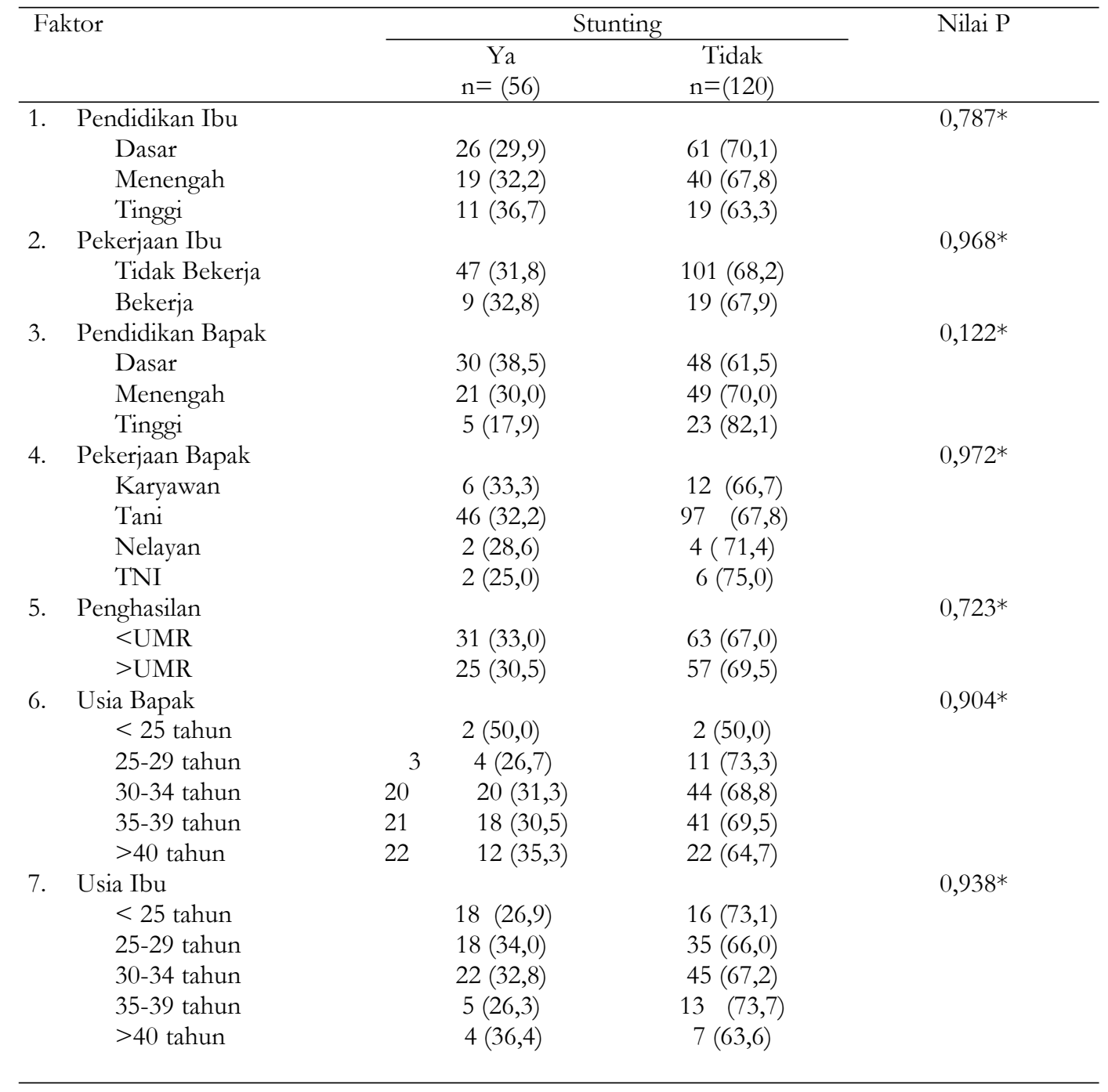

Berdasarkan Tabel 2 karakteristik keluarga mempunyai hubungan signifikan dan bermakna dengan stunting. Pendidikan ibu dasar sejumlah $(29,9 \%)$, pekerjaan ibu tidak bekerja sejumlah $(31,8 \%)$, pendidikan dasar bapak (38,5\%), pekerjaan bapak yang banyak pada pekerjaan tani $(32,2 \%)$, penghasilan keluarga dibawah upah minimum sebanyak $(33,0 \%)$, usia paling banyak pada bapak 30-34 tahun (31,3\%), usia paling banyak pada ibu 30-34 tahun $(32,8 \%)$. Setelah melakukan analisis bivariabel, selanjutnya faktor yang mempunyai nilai $\mathrm{p}<0,25$ dimasukan ke dalam analisis multivariabel dengan menggunakan regresi logistik ganda, adapun variabel yang masuk ke dalam analisis regresi logistik yaitu: pendidikan bapak. 
Tabel 3. Hubungan Karakteristik Anak dengan Kejadian Stunting Pada Anak Umur 6-23 Bulan diWilayah Kerja Puskesmas Pandrah Kabupaten Bireuen Tahun 2019

\begin{tabular}{|c|c|c|c|}
\hline Faktor & \multicolumn{2}{|c|}{ Stunting } & \multirow[t]{2}{*}{ Nilai $\mathrm{P}$} \\
\hline & $\begin{array}{c}\mathrm{Ya} \\
\mathrm{n}=(56)\end{array}$ & $\begin{array}{c}\text { Tidak } \\
\mathrm{n}=(20)\end{array}$ & \\
\hline 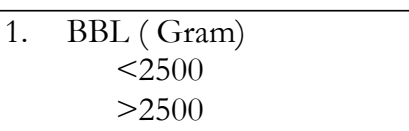 & $\begin{array}{c}53(34,4) \\
3(13,6)\end{array}$ & $\begin{array}{c}101(65,6) \\
19(86,4)\end{array}$ & 0,050 \\
\hline $\begin{array}{l}\text { 2. Pemberian ASI eksklusif } \\
\text { Tidak ASI Ekslusif } \\
\text { ASI Esklusif }\end{array}$ & $\begin{array}{l}4(35,7) \\
51(31,5)\end{array}$ & $\begin{array}{c}9(64,3) \\
111(68,5)\end{array}$ & 0,769 \\
\hline $\begin{array}{l}\text { 3. Kunjungan ANC } \\
<4 \mathrm{x} \\
>4 \mathrm{x}\end{array}$ & $\begin{array}{c}50(48,5) \\
6(8,2)\end{array}$ & $\begin{array}{l}53(51,5) \\
67991,8)\end{array}$ & $<0,001$ \\
\hline $\begin{array}{l}\text { 4. Jenis Kelamin } \\
\text { Laki- laki } \\
\text { Perempuan }\end{array}$ & $\begin{array}{l}28(30,4) \\
28(33,2)\end{array}$ & $\begin{array}{l}64(69,6) \\
56(66,7)\end{array}$ & 0,747 \\
\hline
\end{tabular}

Karakteristik anak mempunyai hubungan signifikan dan bermakna dengan stunting. Berat badan lahir rendah sejumlah 53 (34,4\%), Asi tidak Ekslusif sejumlah 51 (311,5\%), kunjungan ANC $<4 \mathrm{x}$ sejumlah $50(58,5 \%)$, jenis kelamin perempuan 28 $(33,2 \%)$. Setelah melakukan analisis mempunyai nilai $\mathrm{p}<0$,25dimasukan ke dalam analisis multivariabel dengan menggunakan regresi logistik ganda, adapun variabel yang masuk ke dalam analisis regresi logistik ganda diantaranya: berat badan lahir rendah dan kunjungan ANC.

bivariabel, selanjutnya faktor yang

Tabel 4. Analisis Multivariat Faktor- faktor yang berasosiasi dengan Kejadian Stunting berdasarkan regresi logistik ganda Pada Anak Umur 6-23 Bulan diWilayah Kerja Puskesmas Pandrah Kabupaten Bireuen Tahun 2019

\begin{tabular}{lclcc}
\hline Variabel & $\begin{array}{c}\text { Koefisien } \\
\beta\end{array}$ & $\begin{array}{l}\text { SE } \\
\beta\end{array}$ & $\begin{array}{c}\text { Nilai } \\
\mathbf{P}\end{array}$ & $\begin{array}{c}\text { POR (IK 95\%) } \\
\text { adj }\end{array}$ \\
& & & & \\
\hline $\begin{array}{l}\text { Model awal : } \\
\text {-Pendidikan Bapak (R)* }\end{array}$ & 0,449 & 0,614 & 0,465 & $1,57(0,47-5,21)$ \\
-Pendidikan Bapak (M)* & 0,058 & 0,628 & 0,927 & $1,06(0,31-3,63$ \\
& 0,779 & 0,70 & 0,266 & $2,18(0,55-8,60)$ \\
-Berat Badan Lahir (<2500) & 2,296 & 0,472 & $<0,00$ & $10,54(4,20-25,03)$ \\
-Kunjungan ANC & & & & \\
Model Akhir : & $-2,355$ & 0,47 & $<0,00$ & $10,54(4,20-26,44)$ \\
-Kunjungan ANC & &
\end{tabular}

Ket : POR* pendidikan referensinya pendidikan tinggi untuk POR adj (IK95\%) 
Terdapat hubungan signifikan antara Kunjungan ANC dengan kejadian stunting dengan nilai $\mathrm{POR}=10,54(\mathrm{IK} 95 \%: 4,20$ $25,03)$ dan nilai $\mathrm{p}=<0,00$ yang artinya anak yang tidak melakukan kunjungan ANC secara rutin mempunyai risiko 10,54 kali lebih tinggi mengalami stunting dibandingkan dengan anak yang rutin melakukan kunjungan ANC. Pemeriksaan ANC merupakan faktor paling dominan yang berhubungan dengan stunting. Selain kunjungan ANC, berat badan lahir rendah terlihat mempunyai hubungan yang signifikan dengan stunting, ditunjukkan dengan perolehan nilai POR2,18(IK 95\%: $0,55-8,60)$ dan p0,266.

\section{PEMBAHASAN}

\section{Pendidikan Bapak}

Temuan penelitian didapatkan hasil bahwa terdapat hubungan pendidikan bapak dengan stuntingdengan nilai $\mathrm{p}=0,122$ dan $\mathrm{POR}=1,57(0,47-5,21)$. Kesimpulan dari hasil ini adalah pendidikan bapak rendah dan menengah dengan kemungkinan berisiko 1,57 kali mengalami stunting dibandingkan dengan pendidikan tinggi bapak.

Pendidikan adalah suatu proses belajar yang berarti di dalam pendidikan itu terjadi proses pertumbuhan, perkembangan, perubahan kearah yang lebih baik, lebih dewasa dan lebih matang, sehingga dapat menghasilkan perubahan pada diri individu, kelompok atau masyarakat. Hasil penelitian ini sejalan dengan penelitian yang dilakukan lestari dkk yang menunjukkan bahwa tingkat pendidikan ibu tidak berhubungan secara signifikan dengan kejadian stunting pada anak. Penelitian lain juga menunjukkan bahwa pendidikan ibu tidak memiliki hubungan yang bermakna dengan kejadian stunting pada anak usia 1-2 tahun.Pendidikan orang tua sangat penting dalam penyediaan makan bagi anak badutanya, pengetahuan yang diperoleh baik formal maupun nonformal sangat menentukan dalam memilih jenis makanan yang dikonsumsi oleh baduta dan anggota keluarga lainnya. Pendidikan gizi ibu bertujuan meningkatkan penggunaan sumber daya makanan yang bersedia. Dari hal tersebut dapat diasumsikan bahwa tingkat kecukupan energi dan zat gizi pada balita relatif tinggi bila pendidikan gizi ibu tinggi. Pendidikan ibu sangat berperan pada pengetahuan ibu dalam pemilihan bahan makanan bergizi dan pencarian pertolongan pelayanan kesehatan yang dapat mempengaruhi pertumbuhan dan perkembangan anak. Tingkat pendidikan juga mempengaruhi pertumbuhan dan perkembangan anak. Tingkat pendidikan 
juga mempengaruhi keputusan ibu dalam praktik menyusui dan awak penyapihan pada bayi. Tingkat pendidikan sangat berpengaruh terhadap perilaku perubahan sikap dan perilaku hidup sehat. Tingkat pendidikan yang lebih tinggi akan memudahkan seseorang untuk menyerap informasi dan mengimplementasikannya dalam perilaku dan gaya hidup seharihari, khususnya dalam hal kesehatan dan gizi. Tingkat pendidikan khususnya tingkat pendidikan wanita mempengaruhi derajat kesehatan masyarakat. Hasil penelitian ini sejalan dengan hasil temuan dari penelitian Hong (2006) yang menemukan bahwa ibu yang tidak bersekolah dan hanya sampai sekolah dasar (62,6\%) beresiko lebih besar mempunyai anak dengan stunting.

\section{Berat badan lahir}

Temuan penelitian ddidapatkan hasil bahwa terdapat hubungan berat badan lahir rendah dengan stunting pada anak 023 bulan dengan nilai $\mathrm{p}=0,266$ dan POR $=2,18(0,55-8,60)$. Kesimpulan hasil ini adalah berat badan lahir rendah kemungkinan berisiko 2,18 kali untuk mengalami stunting dibandingkan dengan berat badan normal.

Apabila dilihat dari penyebab BBLR dari 53 subjek dengan BBLR sebanyak 34,4\%lahirdengan prematur. Hasil penelitian ini sesuai dengan hasil penelitian lain yang menyatakan bahwa berat badan lahir rendah berhubungan signifikan dengan stunting dan peluang anak yang dilahirkan dengan berat badan lahir rendah berpeluang 19,99 kali mengalami stunting dibandingkan dengan anak yang dilahirkan dengan berat badan normal.

Meskipun berat badan lahir merupakan faktor risiko terjadinya stunting akan tetapi penyebab bayi tersebut lahir dengan berat badan lahir rendah merupakan faktor yang berkontribusi juga terhadap pertumbuhan bayi selanjutnya. Terdapat dua penyebab bayi lahir dengan BBLR yaitu prematuritas dan pertumbuhan janin terhambat(PJT). Pada bayi prematur proses pertumbuhan janin didalam rahim tidak mengalami gangguan, akan tetapi berat badan lahir bayi rendah karena lahir sebelum waktunya dan berat badan sesuai dengan umur gestasi. Pada bayi dengan Intra Uterine Growth Restriction (IUGR) terjadi kegagalan janin untuk mencapai potensi pertumbuhan secara penuh. Bayi pada kelompok ini memiliki risiko 2,9 kali lebih tinggi untuk mengalami laju pertumbahan lebih lambat dibandingkan dengan bayi Prematur. 
Dapat disimpulkan bahwa stunting pada anak dengan riwayat BBLR dapat diminimalisir dengan menjaga kondisi kesehatan anak, sehingga anak dapat melakukan pacu tumbuh untuk mengejar pertumbuhan normal sebelum umur 40 bulan. Sebagian subjek penelitian yang lahir BBLR disebabkan lahir prematuritas bukan karena mengalami pertumbuhan janin terhambat. Selain itu faktor lain seperti asupan nutrisi yang baik dan kondisi kesehatan anak yang baik akan membantu anak dengan riwayat berat badan lahir rendah dapat tumbuh dengan normal.

\section{Riwayat kunjungan ANC}

Temuan penelitian didapatkan hasil bahwa terdapat hubungan riwayat kunjungan ANC dengan kejadian stunting dengan nilai $\mathrm{p}=<0,001$ dengan nilai POR 9,73(3,81-24,87). Kunjungan ANC merupakan faktor risiko baduta stunting di wilayah kerja Puskesmas Pandrah. Kunjungan ANC yang dilakukan secara teratur dapat mendeteksi dini risiko kehamilan yang ada pada seorang ibu terutama yang berkaitan dengan masalah nutrisinya. Pada penelitian ini ditemukan bahwa ibu yang melakukan kunjungan ANC tidak standar memiliki risiko mempunyai balita stunting 2,4 kali dibandingkan ibu yang melakukan kunjungan ANC standar. Kunjungan ANC tidak standar dilihat dari masih ada ibu yang datang memeriksakan kehamilannya ke petugas kesehatan setelah usia kehamilan empat bulan dan tujuh bulan.

Jenis pelayanan ANC pada kunjungan tidak terstandar yang tidak didapatkan ibu selama kehamilan adalah pemeriksaan tinggi badan dan pemeriksaan tinggi badan dan pemeriksaan darah (hemoglobin). Penelitian ini sesuai dengan penelitian yang dilakukan di RSUD Banyumas menunjukkan bahwa ibu yang memiliki kualitas pelayanan antenatal yang kurang baik mempunyai peluang melahirkan bayi dengan berat badan lahir rendah (BBLR) 5,85 kali dibandingkan ibu yang mempunyai kualitas pelayanan antenatal baik karena BBLR merupakan faktor yang berperan dalam kejadian stunting. Melihat pentingnya pemeriksaan ANC terdapat baduta stunting maka diharapkan masyarakat terutama ibu hamil agar memanfaatkan fasilitas pemeriksaan kehamilan semaksimal mungkin agar permasalahan kehamilan terutama yang berhubungan dengan permasalahan nutrisi dapat diketahui sejak awal sehingga dapat dilakukan intervensi lebih 
awal untuk mengatasi permasalahan tersebut.

\section{KESIMPULAN}

Berdasarkan hasil penelitian dan pembahasan mengenai faktor yang berasosiasi dengan kejadian stunting diwilayah Puskesmas Pandrah Kabupaten Bireuen, maka dapat diambil kesimpulan yaitu, terdapat hubungan antara pendidikan bapak, berat badan lahir dan riwayat kunjungan dengan stunting. Melihat pentingnya pemeriksaan ANC terdapat baduta stunting maka diharapkan masyarakat terutama ibu hamil agar memanfaaatkan fasilitas pemeriksaan kehamilan semaksimal mungkin agar permasalahan kehamilan terutama yang berhubungan dengan pemeriksaan nutrisi dapat diketahui sejak awal, sehingga dapat dilakukan intervensi lebih awal untuk mengatasi permasalahan tersebut. Faktor yang paling berhubungan dengan stunting adalah riwayat kunjungan ANC.

\section{SARAN}

Saran untuk penelitian selanjutnya dilakukan penelitian lanjutan dengan menggunakan pendekatan kualitatif sehingga dapat menggali lebih dalam dan didapatkan informasi yang lebih akurat mengenai faktor yang berhubungan dengan stunting, terutama riwayat kunjungan ANC melalui tenaga kesehatan.

\section{UCAPAN TERIMA KASIH}

Kepala dinas kesehatan Bireuen, Kepala Puskesmas dan seluruh bidan desa dan staff ruang gizi dan seluruh pihak yang terlibat dan mendukung terlaksananya penelitian ini.

\section{REFERENSI}

Amin NA, Julia M. (2016). Faktor social deografi dan tinggi badan orang tua serta hubungannya dengan kejadian stunting pada balita usia 6-23 bulan. Jurnal Gizi dan Dietetik Indonesia (Indonesia Journal of Nutrition and Dietetics). 2(3):170-7. associated risk factors. PloS one. 2016;11(5):e0154756.

Almatsier. (2014). Prinsip Dasar Ilmu Gizi. http:// www. goodreads. com/ book/ show/11095785prinsip-dasar-ilmu-gizi, 2011.

Chandra A. (2013). Hubungan underlying factors dengan kejadian stunting pada anak 1-2 th. Journal of Nutrition and Health. 1(1).

Children aged 2.0-4.9 years in Notoatmojo S. (1996). Ilmu kesehatan masyarakat. Jakarta. PT Rineka Cipta.

Cahyono F, Manongga SP, Picauly I. (2016). Jurnal Gizi dan Pangan. 11(1).

Darwati D, Mexitalia M, Hadiyanto S, Hartanto F, Nugraheni S. (2016). Pengaruh Intervensi Konseling Feeding Rules dan Stimulasi Terhadap Status Gizi dan Perkembangan Anak di Posyandu Kabupaten Jayapura. Sari Pediatri. 15(6):377-84. 
García Cruz LM, Gonzalez Azpeitia G, Reyes Suarez D, Santana Rodríguez A, Loro Ferrer JF, Serra-Majem L. (2017). Factors associated with stunting among children aged 0 to 59 months from the central region of Mozambique. Nutrients. 9(5):491.

Indonesia: prevalence trends and Profil Kesehatan Kabupaten Bireuen. 2017.

Maryunani A, Puspita. (2013). Asuhan Kegawatdaruratan Maternal dan Neonatal.Jakarta:TIM.

Medical Sciences (Berkala ilmu Kedokteran). (2012). 44(01).

Najahah, I. Adhi T K. Pinatih, I GN. (2013). Faktor resiko balita stunting usia 12-36 bulan di Puskesmas Dasan Agung, Mataram, Propinsi Nusa Tenggara Barat.

Oktarina Z, Sudiarti T. (2006). Faktor Risiko Stunting Pada Balita (2459 Bulan) Di Liaqat P, Rizvi MA, Oayyum A, Ahamed H, Ishtiaq N. Maternal education and complementary feeding. Pak J Nutr.5(6):563-68.

Pongou R, Ezzati M, Salomon J. (2004). Assesing the Socioeconomic and environmental factors for child nutrition status in Cameroon. Harvard center for population and development studies working paper series. 14(4):2-9.

Profil Kecamatan Pandrah. (2017).

Rahmad AHA, Miko A. (2016). Kajian Stunting pada Anak Balita berdasarkan Pola Asuh dan Pendapatan Keluarga Di Kota Banda Aceh. Kesmas Indonesia. 8(02):58-77.

Richter LM, Victora CG, Hallal PC, Adair LS, Bhargava SK, Fall CH, et al. (2011). Cohort profile: the consortium of health-orientated research in transitioning societies. International journal of epidemiology. 41(3):621-6

Supariasa. (2008). Epidemiologi Gizi, AKZI Malang.

Labada A. (2016). Hubungan karakteristik ibu dengan status gizi balita yang berkunjung di Puskesmas Bahu Manado, 2016 : 3-5 [diakses tanggal 5 Agustus 2018] https://ejournal. unsrat. ac.id/index. $\mathrm{php} / \mathrm{jkp} /$ article/view/11899/11488

Suharyanto ER, puji Hastuti T, Triredjeki H. (2018). Hubungan Status Gizi dengan Perkembangan Anak Usia 1 Sampai 5 Tahun di Kelurahan Tidar Utara Binaan Puskesmas Magelang Selatan Kota Magelang. Jurnal Keperawatan Soedirman. 12(1):27-37.

Rachmi CN, Agho KE, Li M, Baur LA. (2005). Stunting, underweight and overweight in Atmaria. Ketahanan pangan tingkat rumah tangga dn pemenuhan gizi seimbang. Prosiding Temu Ilmiah Konggres XIII PERSAGI;2005; Jakarta: PERSAGI.hlm.318-25.

Sumatera. Jurnal Gizi dan Pangan. 2014;8(3):177-80.

Wandita KHDIS. (2008). Prognostic factors for normal postnatal growth rate in low birth weight infants. Journal of the Sistiarani, C. Faktor maternal dan kualitas pelayanan antenatal yang beresiko terhadap kejadian berat badan lahir rendah (BBLR):Studi pada ibu yang periksa hamil ke tenaga kesehatan dan melahirkan di RSUD Banyumas tahun 200862. Semarang: Fakultas Kesehatan Masyarakat Universitas Diponegoro.

Winkel WS. (1996). Psikologi pengajaran. Jakarta Gramedia Widiasarana Indonesia. 